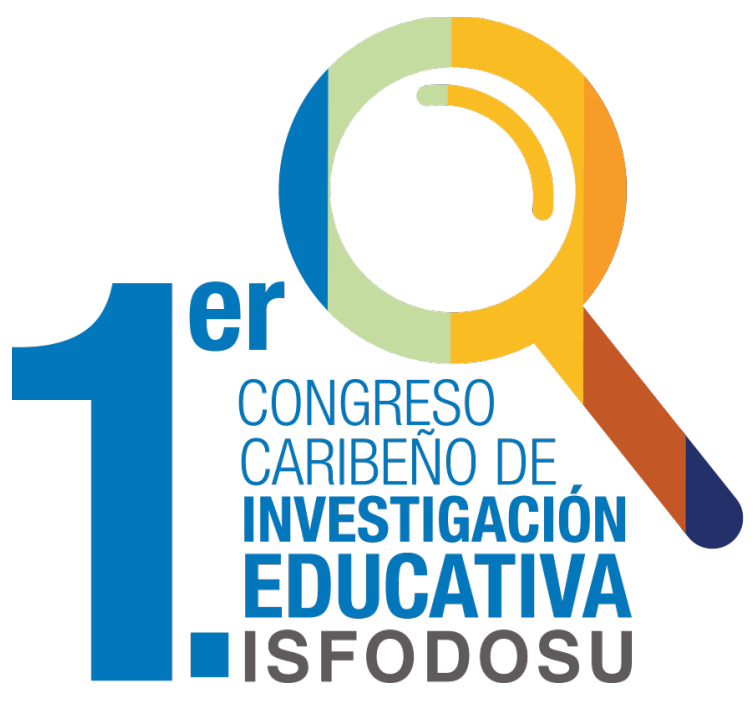




\title{
Nivel de comprensión lectora en estudiantes de Educación Secundaria
}

\author{
Level of Reading Comprehension in Secondary \\ Education Students
}

\author{
Rossanny López de Contreras ${ }^{1} \quad$ Eduardo Encabo Fernández ${ }^{2}$
}

\begin{abstract}
Resumen
El objetivo de esta investigación es analizar el nivel de comprensión lectora de los estudiantes de Educación Secundaria. En este estudio se utilizó un método cuantitativo tipo encuesta, realizada en Bonao, República Dominicana. Una muestra compuesta por 90 estudiantes correspondientes al primer ciclo de Educación Secundaria con edades comprendidas entre 12 y 15 años. El instrumento utilizado fue una prueba de comprensión lectora para cada grado. El nivel de desarrollo presentado por los estudiantes está entre los primeros dos niveles, Insuficiente y Elemental. Las mayores debilidades se presentaron en el tercer grado con un $66.67 \%$ de estudiantes en el Nivel I. Asimismo, el segundo grado presentó los mejores resultados, el $76.67 \%$ de los estudiantes está en el Nivel II.

Estos hallazgos evidencian la gran necesidad de establecer políticas de mejoras educativas, procurando que los estudiantes puedan cerrar esta brecha de aprendizaje que coloca a la República Dominicana en los últimos lugares.
\end{abstract}

Palabras clave: enseñanza secundaria, lectura, calidad de la educación, capacidad lectora, literatura.

\begin{abstract}
Traducir al inglés el resumen. The objective of this investigation is to analyze the level of reading comprehension of the students of Secondary Education. In this study, a quantitative survey-type method was used, carried out in Bonao, Dominican Republic. A sample made up of 90 students corresponding to the first cycle of Secondary Education with ages between 12 and 15 years. The instrument used was a reading comprehension test for each grade.

The level of development presented by the students is between the first two levels, Insufficient and Elementary. The greatest weaknesses were found in the third grade with $66.67 \%$ of students in Level I. Likewise, the second grade presented the best results, $76.67 \%$ of the students are in Level II.

These findings demonstrate the great need to establish educational improvement policies, seeking that students can close this learning gap that places the Dominican Republic in last place.
\end{abstract}

Keywords: secondary education, reading, quality of education, reading ability, literature.

1 Universidad de Murcia (España), ORCID https://orcid.org/0000-0002-3963-6992, correo electrónico: Rossanny.lopezc@um.es

2 Universidad de Murcia (España), ORCID https://orcid.org/0000-0003-2710-2368, correo electrónico: edencabo@.um.es 


\section{Introducción}

Es un gran reto para el sistema educativo dominicano responder a las demandas actuales bajo los principios de calidad, pertinencia y equidad para los estudiantes, compromiso asumido en el Pacto Nacional para la Reforma Educativa (2014), Bases de Revisión y Actualización Curricular (2016) entre otras normativas vigentes. La calidad en el sistema educativo dominicano puede evidenciarse en los resultados obtenidos por los estudiantes en las evaluaciones realizadas a través de: los Estudios Comparativos Regionales, PISA y las Pruebas Nacionales. Los hallazgos obtenidos en estas evaluaciones y otros estudios realizados en el país en comprensión lectora no son los esperados.

Según Jiménez Pérez (2014) la comprensión lectora se define como «la capacidad de un individuo de captar lo más objetivamente posible lo que un autor ha querido transmitir a través de un texto escrito» (p. 71). Existen tres niveles de comprensión lectora según la taxonomía de Bloom: nivel literal o comprensivo, nivel inferencial y nivel inferencial complejo o crítico (Alba R, J., Parrales S, C. \& Iza, S. 2019).

En el marco de los resultados que obtienen los estudiantes en las diversas evaluaciones nacionales e internacionales son puntajes muy bajos en comprensión lectora; es necesario indagar más acerca de la problemática, con el propósito de que se establezcan políticas de mejoras concretas acorde al contexto de cada estudiante. En tal sentido, esta investigación tiene como objetivo principal analizar el nivel de comprensión lectora de los estudiantes de Educación Secundaria y su relación con las variables sociodemográficas.

\section{Fundamentación teórica}

\subsection{Comprensión lectora}

La práctica lectora es de vital importancia para el desarrollo de diversas habilidades, tales como: reconocimiento de palabras y enriquecimiento de su léxico, y con ello desarrollar su capacidad cognitiva para la cimentación de significado de textos (Heit, 2012). Para López Valero \& Encabo Fernández (2013) la comprensión lectora y oral, al igual que la expresión, tienen como finalidad comprender e interpretar el texto construyendo una explicación personal y correcta. Para Durango Herazo (2017) la lectura «se convierte en uno de los temas más destacados de los últimos años por su importancia en los procesos de aprendizaje» (p. 158). El uso de estrategias metacognitivas favorece la comprensión lectora, al igual que la forma de abordar la lectura, el monitoreo y autoevaluación (Zhang \& Wu, 2009). De igual manera, estas estrategias de lectura con sus siglas en inglés (MCRS) componen las bases fundamentales para el desarrollo del enfoque denominado Sirca (Gómez González, 2017).

Existen múltiples factores que inciden en la comprensión lectora, entre los que se encuentran: factores académicos, socioculturales y personales, como lo expresan Franco Montenegro, Cárdenas Rodríguez y Santrich Sánchez (2016), «existe una fuerte correlación entre las actividades realizadas en casa y el nivel de comprensión lectora. El planteamiento central al respecto es que la lectura en los primeros años es fundamental para promover tal habilidad» (p. 6). También existen otros factores para la comprensión de textos que están estrechamente

\footnotetext{
192 Libro de Actas del I.er Congreso Caribeño de Investigación Educativa 2 - Procesos didácticos y de aprendizaje en Ciencias y Humanidades
} 
vinculados entre sí, tales como: factores de comprensión derivados del emisor (manejo del mismo código autor-receptor); factores de comprensión derivados del texto (legibilidad de letras, color, textura del papel, vocabulario, interés del autor, entre otros. Para Aristy-Escuder (2016) un factor influyente en el rendimiento en pruebas nacionales en los estudiantes es la importancia de que los niños tengan la oportunidad de cursar el Nivel Inicial.

El desarrollo de la competencia comunicativa se concibe como un conjunto de habilidades que favorece un mejor desenvolvimiento del ser humano ante situaciones comunicativas concretas. Según García Molina (2011, p. 18), es fundamental que se fomente en los estudiantes las competencias que «son indispensables para la comunicación eficaz». En el caso de la educación dominicana, el desarrollo de las competencias específicas de comprensión oral y escrita es un reto dada la implementación del diseño curricular actual.

En un estudio realizado por Bizama Muñoz, García Ferrero, Aqueveque, Arancibia Gutiérrez y Sáez Carrillo (2020) encontraron que la comprensión de textos informativos está asociada de forma significativa estadísticamente con la inteligencia fluida, inhibición y memoria de trabajo.

En el país se han realizado investigaciones con respecto a la comprensión lectora, una de ellas es la que realizó el Ministerio de Educación (2018) y el Instituto Dominicano de Evaluación de la Calidad Educativa. En este estudio participaron docentes del Nivel Inicial y primer ciclo de Educación Primaria; los resultados revelaron bajo nivel de comprensión lectora por parte de los docentes, con un puntaje promedio de 9.98 de 26 y es más significativo en los niveles inferencial y crítico. Además, el Ministerio de Educación recientemente reveló los resultados sobre la Evaluación diagnóstica nacional de Sexto Grado de Educación Primaria, los cuales fueron poco satisfactorios; solo un $23 \%$ de los estudiantes alcanzaron el nivel satisfactorio. Según el Reporte USEPE N. ${ }^{\circ} 3$ MINERD-Ideice (2020) los resultados de la Prueba PISA de los estudiantes en el país oscilan en un puntaje promedio en comprensión lectora de 341.63 y solo el $21 \%$ de los estudiantes quedó en el Nivel II en comprensión lectora.

\section{Metodología}

El objetivo de esta investigación fue analizar el nivel de comprensión lectora de los estudiantes de Educación Secundaria y su relación con las variables sociodemográficas. El enfoque metodológico de este estudio fue cuantitativo, no experimental, transversal y de corte descriptivo.

\subsection{Población y muestra}

El universo del estudio es de 2,375 participantes. Para esta prueba piloto se tomó una muestra intencional de 90 estudiantes, 30 estudiantes por cada grado del primer ciclo de Educación Secundaria. El criterio de selección de la muestra fue de tipo no probabilístico intencionada, los participantes debían cumplir unos criterios previamente definidos que no contaminen la investigación definitiva. 


\section{Tabla 1}

Distribución de la muestra por centro educativo y nivel educativo

\begin{tabular}{l|c|c|c|c}
\multicolumn{1}{c|}{ Centro Educativo } & Muestra & Género & Grado & Nivel \\
\hline Prof. María Batista & 8 & $\mathrm{~F}$ & $1 .{ }^{\circ}$ & Primario/servicio Secundario \\
Bienvenido del Castillo & 9 & $\mathrm{M}$ & $1 .^{\circ}$ & Primario/servicio Secundario \\
Ercilia Pepín Estrella & 8 & $\mathrm{~F}$ & & \\
Antonio Rosario Pérez & 8 & $\mathrm{M}$ & $2 .^{\circ}$ & Primario/servicio Secundario \\
Hermanas Mirabal & 1 & $\mathrm{M}$ & $2 .^{\circ}$ & Primario/servicio Secundario \\
Eunice Deyanira Mateo & 2 & $\mathrm{~F}$ & $2 .^{\circ}$ & Primario/servicio Secundario \\
Cigar Family & 9 & $\mathrm{M}$ & $3 .{ }^{\circ}$ & Secundario \\
\hline
\end{tabular}

\subsection{Instrumentos}

Los instrumentos utilizados en este estudio fueron tres pruebas de comprensión lectora tipo test. Para el diseño de las pruebas se solicitó el permiso a la encargada de la Dirección de Evaluación de la Calidad, Ancell Scheker Mendoza, para utilizar los ítems liberados de las pruebas nacionales. Las pruebas fueron elaboradas por los autores Rossanny López y Eduardo Encabo, para su diseño y elaboración también fueron tomados en cuenta los contenidos del Diseño curricular revisado y actualizado. Posteriormente fueron sometidas a juicio de expertos en el área.

Las categorías para cada nivel de comprensión lectora están organizadas de la siguiente manera: categoría Insuficiente para los estudiantes que solo alcanzaron el nivel literal; categoría Elemental para los estudiantes que alcanzaron el nivel literal e inferencial simple y la categoría Satisfactoria para los estudiantes que lograron los niveles mencionados y el nivel inferencial complejo. Cada prueba tiene un valor de 20 puntos, distribuidos para cada categoría. 
Tabla 2

Correspondencia tipo de texto según grado

\begin{tabular}{c|c|c|c} 
& Primero & Segundo & Tercero \\
\hline \multirow{3}{*}{ Tipo de textos } & Conversacional & Expositivo & Argumentativo \\
& Expositivo & Directivo & Directivo \\
& Literario & Literario & Literario \\
\hline
\end{tabular}

\subsection{Procedimiento de recogida y análisis de datos}

Para la obtención de los resultados de esta prueba piloto la información fue recogida a través de los instrumentos diseñados para cada grado. Previamente se obtuvo el permiso escrito otorgado por el distrito correspondiente y la aceptación por parte de los diferentes centros educativos. Un equipo de técnicos distritales y del equipo de gestión de cada centro educativo colaboró con la aplicación de las pruebas. Para el posterior análisis de los datos fue utilizado el programa estadístico SPSS versión 25.0, siendo aplicados diversos tipos de análisis descriptivos.

\section{Resultados}

A continuación, se presentan en un primer apartado los resultados concernientes a los aspectos sociodemográficos, luego el nivel de comprensión lectora alcanzado por los estudiantes del primer ciclo de Educación Secundaria.

La edad de los estudiantes de primer grado en su mayoría es de 12 años, para un porcentaje de $76.7 \%(n=23)$, siendo esta la edad teórica indicada acorde a la estructura del currículo dominicano actualizado, mientras el restante $23.3 \%(n=7)$ posee 13 años. Los estudiantes de segundo grado presentaron una mayor frecuencia de edad de 13 años, con un porcentaje de $86.7 \%(n=26)$ quedando un $13.3 \%(n=4)$ con 14 años. Para los estudiantes de tercer grado hubo una frecuencia significativa en la edad de 14 años con un $96.7 \%(n=29)$, edad esperada por el Ministerio de Educación dominicano para tercer grado, tan solo un estudiante estaba por encima de la edad requerida.

Con relación al género, se observa que el género femenino representa la mayoría en los grados segundo y tercero; en el primer grado el porcentaje pasa del $50 \%$ de los participantes masculinos, sin embargo, en segundo grado el género femenino alcanza el $80 \%$ vs. $66.7 \%$ en tercer grado.

La mayoría de los estudiantes de los tres grados viven en la zona rural, con un porcentaje superior al $50 \%$ para todos los grados. En un primer lugar se privilegia la zona rural. El primer grado posee el $50 \%(n=15)$, en segundo grado el porcentaje es mayor con un $63.3 \%$ $(n=19)$ y en tercer grado un $66.7 \%(n=20)$; a estos resultados le sigue en segundo lugar las zonas: urbana marginal y urbana. 
Para el primer grado de Educación Secundaria, el nivel de logro de los estudiantes fue de un $53 \%(n=16)$ para la categoría Insuficiente y el restante $46.67 \%(n=14)$ en la categoría Elemental, quedando en evidencia que no hubo ningún estudiante en la categoría de Satisfactorio.

El segundo grado es el único que mínimamente posee un $6.67 \%$ en la categoría de Satisfactorio $(n=2)$, sin embargo, al igual que los demás grados la gran mayoría de los estudiantes se encuentran en la categoría Elemental $(n=23)$ y el restante $16.67 \%(n=5)$ queda en la categoría Insuficiente.

Con respecto al tercer grado, los resultados fueron los siguientes: un $66.67 \%(n=20)$ de los estudiantes están en la categoría Insuficiente, categoría donde se encuentra el mayor porcentaje, el mismo supera más de la mitad de los participantes. El $33.33 \%(n=10)$ faltante está en la categoría Elemental.

\section{Conclusiones}

La lectura lleva al ser humano a la construcción de su propio criterio frente a una información dada en la vida cotidiana. Leer no solo es pasar la vista por las letras o memorizar párrafos textuales, la lectura significa comprender, interpretar, inferir, extraer conclusiones y sacar conclusiones sobre un texto dado.

Los datos presentes en este estudio revelan los hallazgos encontrados al analizar el nivel de comprensión lectora de los estudiantes de Educación Secundaria y relacionarlo con los aspectos sociodemográficos. En este sentido, el puntaje promedio para el primer grado fue de 6 a 7 puntos de un total de 20, esto ubica a este grado en la categoría de Insuficiente, mientras que el segundo grado alcanzó un puntaje de 8 a 10 puntos, quedando en la categoría Elemental y el tercer grado obtuvo un puntaje de 6 a 7 puntos, con un $10 \%$ de participantes que solo consiguió de 4 a 5 puntos. El tercer grado, al igual que el primero, está en la categoría Insuficiente.

Respecto a las edades que poseen los participantes, muestran una desigualdad con las señaladas por el Ministerio de Educación dominicano, según la Ordenanza 03-2013, la cual para el primer grado de Educación Secundaria establece la edad de 12 años, sin embargo, un $23.3 \%$ de los estudiantes que participaron en esta investigación tiene 13 años. Del mismo modo, existen ligeras diferencias en este aspecto con los grados segundo y tercero. En este sentido, los resultados de la Prueba Pisa (2018) al evaluar la correspondencia entre la edad teórica de 15 años (llamada también grado modal) de acuerdo a los resultados del informe, los estudiantes con la edad correspondiente obtuvieron calificaciones más significativas comparados con otros grados superiores o inferiores.

Con relación al género, se visualiza que el género femenino posee mayor frecuencia, específicamente en segundo y tercer grado. Las niñas obtuvieron mayor puntaje que los niños en comprensión lectora, estos resultados coinciden con la evaluación Pisa (2018) donde el género femenino obtuvo puntajes superiores a sus pares masculino. Este patrón es similar en los países latinoamericanos, en el caso de los estudiantes dominicanos las diferencias son aún más marcadas a favor del género femenino.

\footnotetext{
196 LJE 2 - Procesos didácticos y de aprendizaje en Ciencias y Humanidades
} 
Siguiendo con la zona donde viven los estudiantes, los hallazgos encontrados en los grados segundo y tercero más del $60 \%$ de los estudiantes pertenecen a la zona rural y el primer grado con un $50 \%$. El Distrito16-06 posee la mayor cantidad de centros educativos ubicados en la zona rural, seguido de la zona urbana marginal, coincidiendo con los diferentes estudios realizados en dicho distrito, predominando la zona rural por su ubicación geográfica de sus centros educativos.

\section{Referencias bibliográficas}

Alba R, J., Parrales S, C., \& Iza, S. (2019). Comprensión lectora apoyada en la taxonomía de Bloom. Búsqueda del desarrollo del pensamiento crítico en universitarios. Revista Científica Ciencia y tecnología, 18(20). http://cienciaytecnologia.uteg.edu.ec/revista/index.php/cienciaytecnologia/ article/view/487

Aristy-Escuder, J. (2016). Impacto de la Educación Inicial sobre el desempeño escolar en la República Dominicana. Santo Domingo: IDEICE.

Bizama Muñoz, M., García Ferrero, S., Aqueveque, C., Arancibia Gutiérrez, B., \& Sáez Carrillo, K. (2020). Comprensión de lectura de textos informativos de carácter científico en escolares. Revistas de Estudios sobre la Lectura, 19(1), 68-79.

Durango Herazo, Z. R. (2017). Niveles de comprensión lectora en los estudiantes de la Corporación Universitaria Rafael Núñez (Cartagena de Indias). Revista virtual Universidad Católica del Norte, (51), 156-174.

Franco Montenegro, M. P., Cárdenas Rodríguez, R., \& Santrich Sánchez, E. R. (2016). Factores asociados a la comprensión lectora en estudiantes de noveno grado de Barranquilla. Psicogente, 19(36), 296-310.

García Molina, B. (2011). Competencias Comunicativas. Lengua Española para Nivelación. Santo Domingo, República Dominicana: Surco.

Gómez González, J. D. (2017). A model for the Strategic Use of Metacognitive Reading Comprehension Strategies. Profile: Issues in Teachers" Profesional Development, 19(2), 187-201.

Gutiérrez Fresneda, R. (2016). La lectura Dialógica como medio para la mejora de la Comprensión Lectora. Investigaciones sobre la Lectura (5), 52-58.

Heit, I. (2012). Estrategias Metacognitivas de Comprensión Lectora y Eficacia en la asignatura Lengua y Literatura. Revista de Psicología, 08(15), 79-96.

Jiménez Pérez, E. (2014). Comprensión lectora vs Competencia lectora: qué son y qué relación existe entre ellas. Investigaciones sobre Lectura (ISL)(1), 65-74.

López Valero, A. y Encabo Fernández, E. (2013). Fundamentos Didácticos de la Lengua y la Literatura. Madrid: SÍNTESIS.

Ministerio de Educación dominicano. (2018). Informe Resultados Pruebas Nacionales. Santo Domingo.

Ministerio de Educación República Dominicana. (2016). Bases de la Revisión y Actualización Curricular. Santo Domingo, D.N.: Editora Centenario.

Ordenanza 03-2013 [Ministerio de Educación dominicano] mediante la cual se modifica la Estructura Académica del Sistema Educativo Dominicano, estableciendo tres (3) niveles educativos de seis (6) años cada uno, subdivididos en dos (2) ciclos de tres (3) años, que entrarán en vigencia por etapas. 